\title{
Pengaruh Insentif Terhadap Produktivitas Kerja Karyawan CV. CST Virtual System Singapore Region Sumatera
}

\author{
Oktariansyah \\ Akuntansi, Fakultas Ekonomi Universitas PGRI Palembang \\ Email : rianbro82@univpgri-palembang.ac.id
}

\begin{abstract}
ABSTRAK
Penelitian ini bertujuan untuk menunjukkan signifikansi pengaruh insentif terhadap produktivitas kerja karyawan. Teknik analisis meliputi analisis koefisien korelasi,regresi linier sederhana, koefisien determinasi dan penguji hipotesis dan uji t. Persamaan koefisien korelasi sebesar 0,736 berarti kuat, maksudnya jika insentif meningkat maka variabel produktivitas kerja juga meningkat dan sebaliknya jika variabel insentif menurun maka variabel produktivitas kerja menurun.Koefisien determinasi $54,17 \%$ berarti kontribusi variabel insentif terhadap produktivitas kerja sebesar $54,17 \%$, sedangkan sisanya $45,83 \%(100 \%-54,17 \%)$ dijelaskan oleh variabel lain yang tidak diteliti dalam penelitian ini. Menunjukkan hasil penelitian regresi linier sederhana adalah $Y^{\prime}=6,666+0,832 X$ dan penguji hipotesis dengan menggunakan uji $t$ dan taraf nyata $5 \%$ diperoleh kesimpulan bahwa terdapat pengaruh insentif terhadap produktivitas kerja pada CV CST Virtual System Singapore Region Sumatera. Dari hasil perhitungan diperoleh thitung sebesar 7,924 dan hasil uji t ini signifikan karena thitung sebesar 7,924 > 2,020 maka menghasilkan keputusan bahwa Ho ditolak dan Ha diterima, berarti terdapat pengaruh insentif terhadap produktivitas kerja pada CV CST Virtual System Singapore Region Sumatera.
\end{abstract}

Kata Kunci : Insentif, Produktivitas Kerja.

\section{A. Latar Belakang}

Sumber daya manusia memegang berperan penting dalam kemajuan dan perkembangan perusahaan. $\mathrm{Di}$ era globalisasi ini perusahaan harus cekatan dalam menetapkan manajemen yang baik nan uggul terutama dalam sumber daya manusia, dalam bidang manajemen tenaga kerja. Saat ini kemajuan dan perkembangan perusahaan sudah sangat pesat, sehingga menciptakan kondisi yang kompetitif baik di dalam perusahaan maupun diluar perusahaan,kondisi tersebut akan menuntut suatu organisasi atau perusahaan untuk selalu melakukan inovasi guna mengantisipasi adanya persaingan yang semakin ketat, maka sudah seharusnya SDM mendapat perhatian khusus, karena manusia yang menentukan hasil dari kinerja perusahaan yaitu keberhasilan atau kegagalan. Untuk dapat melakukan kelangsungan hidup tersebut perusahaan harus dapat dan mampu menjalankan manajemen yang baik dan mampu melakukan kerja sama secara efektif dan efisien.

Perusahaan dalam melakukan aktivitasnya mempunyai tujuan yang hendak dicapai, namun pada prinsipnya hanya ada satu tujuan dasar perusahaan yaitu ingin mendapatkan laba yang besar sehingga kelangsungan hidup perusahaan bisa terjamin. Untuk dapat melaksanakan tugas dan fungsinya dengan sebaik mungkin maka dibutuhkan karyawan dengan kerja yang baik bagi perusahaan. Dari kinerja yang baik, karyawan dapat meningkatkan penjualan yang mungkin melampaui target. Dari Hasil penjualan yang telah melampaui target membuat karyawan mendapatkan insentif dari hasil 
penjualan tersebut. Sehingga dengan adanya pemberian insentif yang diberikan kepada karyawan membuat produktivitas kerja yang dihasilkan pun sangat baik bagi perusahaan.

Untuk mewujudkan kondisi seperti ini terutama dalam bidang sumber daya manusia yang baik harus dapat mempelajari, memahami serta menerapkan unsur - unsur manajemen didalam pola kerjanya sehingga dapat mempengaruhi dan memotivasi karyawan sehingga dapat meningkatkan produktivitas kerja karyawan dengan memberikan insentif bagi karyawan yang berprestasi. Menurur Sulistiyani (2010: 315) Produktivitas kerja adalah suatu sikap dan prilaku karyawan dalam birokrasi terhadap peraturan-peraturan dan standar-standar yang telah ditetapkan oleh birokrasi yang telah diwujudkan baik dalam bentuk tingkah laku mupun perbuatan.

Insentif dapat diartikan sebagai bentuk pembayaran yang dikaitkan dengan kinerja,sebagai pembagian keuntungan bagi karyawan akibat peningkatan produktivitas atau penghematan biaya.Sistem ini merupakan bentuk kompensasi langsung di luar gaji atau upah yang merupakan kompensasi tetap, yang disebut kompensasi berdasarkan kinerja (Rivai,2009:766).

Menurut Suwatno dan Priansa (2011:234) Insentif merupakan suatu yang merangsang minat untuk bekerja.Pemahaman ini merupakan pendapat yang baik apabila diterapakan pada suatu perusahaan,karena kinerja dan produktivitas perusahaan akan meningkat, hal tersebut akibat dari karyawan yang bekerja dengan optimal.

Menurut Yani (2012: 146) Insentif penghargaan dalam bentuk uang yang di berikan oleh suatu organisasi atau Perusahaan kepada karyawanya atas dasar prestasi kerja yang tinggi atau pada karyawannya yang bekerja melampaui standar yang telah ditentukan.

Adanya sistem pemberian insentif yang diharapkan dapat mendorong dan mengarahakan seseorang dapat merpikir secara logis mengkaitkan insentif dari kerja.Arah dari programprogram adalah memperlakukan mereka sebagai mitra dan membuat mereka berpikir tentang bisnis seperti milik mereka sendiri. Pelaksanaaan sistem upah insentif diberikan perusahaan terutama untuk meningkatkan produktivitas karyawan serta mempertahankan karyawan yang berprestasi untuk tetap bekerja dalam perusahaan, dengan demikian apabila seseorang bersedia bekerja dengan giat sehingga dapat mencapai produktivitas kerja yang tinggi maka akan memperoleh imbalan pendapatan yang tinggi pula atas prestasi kerjanya.

Perkembangan perusahaan yang bergerak dalam bidang pelayanan jasa ini awalnya hanya melayani service alat berat, berkat kerja sama antara pemilik dan karyawanya perusahaan ini mulai menjual peralatan dan suku cadang alat berat secara lengkap. Dalam mencapai tujuan perusahaan baik tujuan jangka pendek maupun jangka panjang perusahaan perlu memanajemen produktivitas kerja agar sesuai dengan visi dan misi perusahaan.

Untuk mencapai hasil yang diinginkan perusahaan harus mempunyai karyawan yang kinerjanya tinggi dan baik sehinga dapat meningkatkan produktivitas kerja.dengan itu perusahaan dapat memberikan insentif pada karyawan yang berprestasi.

Berdasarkan hasil wawancara pada CV CST Virtual System Singapore Region Sumatera, masalah 
insentif yang diberikan oleh CV CST Virtual System Singapore Region Sumatera masih kurang efektif. Dengan hal ini karyawan cendrung kurang bersemangat dalam bekerja, sehingga mengakibatkan adanya penurunan produktivitas kerja.

\section{B. Rumusan Masalah}

Berdasarkan penjelasan dari latar belakang diatas yaitu Adakah Pengaruh Insentif Terhadap Produktivitas Kerja Karyawan pada CV CST Virtual System Singapore Region Sumatera.

\section{Metode Penelitian}

Menurut Sugiyono

(2010:13) mengemukakan metode penelitian kuantitatif dapat diartikan sebagai metode penelitian yang berdasarkan pada filsafat positivisme, teknik pengambilan sampel pada umumnya dilakukan secara random, pengumpulan data menggunakan instrumen penelitian, analisis data bersifat kuantitatif atau statistik dengan tujuan untuk menguji hipotesis yang telah di tetapkan.

\section{Populasi dan Sampel}

1) Populasi

Populasi adalah wilayah generalisasi yang terdiri atas objek/subjek yang mempunyai kualitas dan karakteristik tertentu yang ditetapkan oleh peneliti untuk dipelajari dan ditarik kesimpulannya. (Sugiyono, 2010 : 80) .

Adapun Populasi yang penulis teliti adalah karyawan di CV CST Virtual System Singapore Region Sumatera.

\section{2) Sampel}

Menurut Sugiyono (2010 : 116) Sampel adalah bagian dari jumlah dan karakteristik yang dimiliki oleh populasi tersebut.karena keterbatasan populasi maka peneliti mengunakan teknik sampling jenuh.

Teknik sampling jenuh adalah teknik penentuan sampel bila semua anggota populasi digunakan sebagai sampel. Jadi sampel yang digunakan oleh peneliti adalah seleruh jumlah karyawan yaitu 43 responden.

\section{E. Teknik Pengumpulan Data}

1) Observasi

Observasi adalah Kegiatan pengamatan, meliputi kegiatan pemusatan perhatian terhadap suatu objek yang menggunakan seluruh alat panca Indra yang dapat dilakukan melalui indra penglihatan, pendengaran, penciuman, peraba dan pengecap (Arikunto, 2010 : 101). Observasi dilakukan dengan melakukan pengamatan secara langsung di CV. CST Virtual System Singapore Region Sumatera.

2) Wawancara

Wawancara (Interview), yaitu pengambilan data dilakukan dengan wawancara langsung dengan pimpinan ataupun dengan pihak-pihak yang mampu memberikan informasi yang dibutuhkan dari peusahaan sebagai bahan penelitian. (Sugiyono,2010:141)

3) Kuesioner

Kuesioner adalah Teknik pengumpulan data yang dilakukan dengan cara memberi seperangkat peryataan atau pertanyaan tertulis kepada reponden untuk dijawabnya. (Sugiyono, 2010 : 142 ).

\section{F. Teknik Analisis Data}

Teknik analisis data penelitian ini bersifat kuantitatif atau statistik dengan 
tujuan untuk menguji hipotesis yang telah di tetapkan. Sugiyono (2010:13).

\section{G. Hasil Penelitian dan Pembahasan}

1) Hasil Uji Validitas Variabel Insentif (X)

Uji validitas adalah untuk mengetahui sejauh mana suatu alat ukur mampu mengukur apa yang ingin diukur. Uji validitas diperoleh dengan cara mengkorelasikan setiap skor indikator dengan total skor indikator variabel, kemudian hasil korelasi dibandingkan dengan nilai kritis pada taraf signifikan 0.05.

Suatu instrumen dikatakan valid apabila mampu mengukur apa yang diinginkan dan tinggi rendahnya validitas instrument menunjukan sejauh mana data yang terkumpul tidak menyimpang dari gambaran tentang variabel yang dimaksud. Cara yang digunakan adalah dengan analisis item, yaitu mengkorelasikan tiap skor, tiap butir dengan skor total yang merupakan jumlah tiap skor butir.

\section{A. Menghitung Pearson's Product Moment}

Berikut menghitung pearson's product moment dalam setiap butir item Variabel Insentif ( $X$ ) :

\section{Butir Item 1}

$$
\begin{aligned}
& r_{x y}=\frac{n \sum x y-\left(\sum x\right)\left(\sum y\right)}{\sqrt{\left[n \sum x^{2}-\left(\sum x\right)^{2}\right]\left[n \sum y^{2}-\left(\sum y\right)^{2}\right]}} \\
& r_{x y}=\frac{43.6526-(173)(1605)}{\sqrt{\left.\left[43.709-(173)^{2}\right] 43.60797-(1605)^{2}\right]}} \\
& r_{x y}=\frac{280618-(277665)}{\sqrt{[(30487-29929)(2614271-2576025)]}} \\
& r_{x y}=\frac{2953}{\sqrt{21351870}}=\frac{2953}{4620.808371} \\
& r_{x y}=0,63906567052=\mathbf{0 , 6 3 9}
\end{aligned}
$$

\section{Butir Item 2}

$$
\begin{aligned}
& r_{x y}=\frac{n \sum x y-\left(\sum x\right)\left(\sum y\right)}{\sqrt{\left[n \sum x^{2}-\left(\sum x\right)^{2}\right]\left[n \sum y^{2}-\left(\sum y\right)^{2}\right]}} \\
& r_{x y}=\frac{43.6355-(168)(1605)}{\sqrt{\left.\left[43.678-(168)^{2}\right] 43.60797-(1605)^{2}\right]}} \\
& r_{x y}=\frac{273265-(269640)}{\sqrt{[(29154-28224)(2614271-2576025)]}} \\
& r_{x y}=\frac{3625}{\sqrt{35568780}}=\frac{3625}{5963,95674} \\
& r_{x y}=0,60781795677=\mathbf{0 , 6 0 8}
\end{aligned}
$$

\section{Butiran Item 3}

$$
\begin{aligned}
& r_{x y}=\frac{n \sum x y-\left(\sum x\right)\left(\sum y\right)}{\sqrt{\left[n \sum x^{2}-\left(\sum x\right)^{2}\right]\left[n \sum y^{2}-\left(\sum y\right)^{2}\right]}} \\
& r_{x y}=\frac{43.5145-(134)(1605)}{\sqrt{\left[43.466-(134)^{2}\left[43.60797-(1605)^{2}\right]\right.}} \\
& r_{x y}=\frac{221235-(215070)}{\sqrt{[(20038-17956)(2614271-2576025)]}} \\
& r_{x y}=\frac{6165}{\sqrt{79666418}}=\frac{6165}{8925,604629} \\
& r_{x y}=0,69070951002=\mathbf{0 , 6 9 1}
\end{aligned}
$$

\section{Butir Item 4}

$$
\begin{aligned}
& r_{x y}=\frac{n \sum x y-\left(\sum x\right)\left(\sum y\right)}{\sqrt{\left[n \sum x^{2}-\left(\sum x\right)^{2}\right]\left[n \sum y^{2}-\left(\sum y\right)^{2}\right]}} \\
& r_{x y}=\frac{43.5994-(158)(1605)}{\sqrt{\left.\left[43.602-(158)^{2}\right] 43.60797-(1605)^{2}\right]}} \\
& r_{x y}=\frac{257742-(253590)}{\sqrt{[(25886-24964)(2614271-2576025)]}} \\
& r_{x y}=\frac{4152}{\sqrt{35262812}}=\frac{4152}{5938,249911} \\
& r_{x y}=0,69919590152=\mathbf{0 , 6 9 9}
\end{aligned}
$$

\section{Butir Item 5}

$$
\begin{aligned}
& r_{x y}=\frac{n \sum x y-\left(\sum x\right)\left(\sum y\right)}{\sqrt{\left[n \sum x^{2}-\left(\sum x\right)^{2}\right]\left[n \sum y^{2}-\left(\sum y\right)^{2}\right]}} \\
& r_{x y}=\frac{43.6060-(160)(1605)}{\left.\sqrt{\left[43.618-(160)^{2}\left[43.60797-(1605)^{2}\right.\right.}\right]}
\end{aligned}
$$




$$
\begin{aligned}
& r_{x y}=\frac{260580-(256800)}{\sqrt{[(26574-25600)(2614271-2576026)]}} \\
& r_{x y}=\frac{3780}{6103,329419}=0,61933409463=\mathbf{0 , 6 1 9}
\end{aligned}
$$

\section{Butir Item 6}

$$
\begin{aligned}
r_{x y} & =\frac{n \sum x y-\left(\sum x\right)\left(\sum y\right)}{\sqrt{\left[n \sum x^{2}-\left(\sum x\right)^{2}\right]\left[n \sum y^{2}-\left(\sum y\right)^{2}\right]}} \\
r_{x y} & =\frac{43.5985-(158)(1605)}{\sqrt{\left[43.608-(158)^{2}\left[43.60797(1605)^{2}\right]\right.}} \\
r_{x y} & =\frac{257355-(253590)}{\sqrt{[(26144-24864)(2614271-2576025)]}} \\
r_{x y} & =\frac{3765}{\sqrt{48954880}}=\frac{3765}{6996,776401} \\
r_{x y} & =0,53810494779=\mathbf{0 , 5 3 8}
\end{aligned}
$$

\section{$6 \quad$ Butir Item 7}

$$
\begin{aligned}
& r_{x y}=\frac{n \sum x y-\left(\sum x\right)\left(\sum y\right)}{\sqrt{\left[n \sum x^{2}-\left(\sum x\right)^{2}\right]\left[n \sum y^{2}-\left(\sum y\right)^{2}\right]}} \\
& r_{x y}=\frac{43.5855-(155)(1605)}{\sqrt{[43.597-(155)]\left[43.60797-(1605)^{2}\right]}} \\
& r_{x y}=\frac{251765-(248775)}{\sqrt{[(25671-24025)(2614271-2576025)]}} \\
& r_{x y}=\frac{2990}{\sqrt{63029408}}=\frac{2990}{7939,106247} \\
& r_{x y}=0,37661670054=\mathbf{0 , 3 7 7}
\end{aligned}
$$

\section{$7 \quad$ Butir Item 8}

$$
\begin{aligned}
& r_{x y}=\frac{n \sum x y-\left(\sum x\right)\left(\sum y\right)}{\sqrt{\left[n \sum x^{2}-\left(\sum x\right)^{2}\right]\left[n \sum y^{2}-\left(\sum y\right)^{2}\right]}} \\
& r_{x y}=\frac{43.5622-(148)(1605)}{\sqrt{\left[43.532-(148)^{2}\left[43.60797-(1605)^{2}\right]\right.}} \\
& r_{x y}=\frac{241746-(237540)}{\sqrt{[(22876-21904)(2614271-2576025)]}}
\end{aligned}
$$

$$
\begin{aligned}
& r_{x y}=\frac{4206}{37175112}=\frac{4206}{6097,139657} \\
& r_{x y}=0,68983166478=\mathbf{0 , 6 9 0}
\end{aligned}
$$

\section{Butir Item 9}

$$
\begin{aligned}
& r_{x y}=\frac{n \sum x y-\left(\sum x\right)\left(\sum y\right)}{\sqrt{\left[n \sum x^{2}-\left(\sum x\right)^{2}\right]\left[n \sum y^{2}-\left(\sum y\right)^{2}\right]}} \\
& r_{x y}=\frac{43.5676-(174)(1605)}{\sqrt{\left.\left[43.724-(174)^{2}\right] 43.60797-(1605)^{2}\right]}} \\
& r_{x y}=\frac{282768-(279270)}{\sqrt{[(31132-30276)][(2614271-2576025)]}} \\
& r_{x y}=\frac{3498}{\sqrt{32738576}}=\frac{3498}{5721,763365} \\
& r_{x y}=0,61134999419=\mathbf{0 , 6 1 1}
\end{aligned}
$$

\section{Butir Item 10}

$$
\begin{aligned}
& r_{x y}=\frac{n \sum x y-\left(\sum x\right)\left(\sum y\right)}{\sqrt{\left[n \sum x^{2}-\left(\sum x\right)^{2}\right]\left[n \sum y^{2}-\left(\sum y\right)^{2}\right]}} \\
& r_{x y}=\frac{43.6679-(177)(1605)}{\sqrt{\left.\left[43.749-(177)^{2}\right] 43.60797-(1605)^{2}\right]}} \\
& r_{x y}=\frac{287197-(284085)}{\sqrt{[(32207-31329)](2614271-2576025)]}} \\
& r_{x y}=\frac{3112}{\sqrt{33579988}}=0,53703095556=\mathbf{0 , 5 3 7} \\
& \text { B. Menentukan } r \text { tabel Insentif }(X)
\end{aligned}
$$

Menentukan $r_{\text {tabel }}$ jika diketahui signifikan pada taraf nyata $\alpha=0,05$ dan $\mathrm{n}=43$, maka diperoleh $r_{\text {tabel }}=$ 0,301 (lihat tabel nilai-nilai $r$ product Moment).

C. Menentukan Keputusan Uji

Tabel berikut ini menyajikan keputusan uji validitas variabel Insentif 
TABEL 1

KEPUTUSAN UJI VALIDITAS VARIABEL INSENTIF

\begin{tabular}{|c|c|c|c|}
\hline $\begin{array}{c}\text { Nomor Item } \\
\text { Pertanyaan }\end{array}$ & $\begin{array}{c}\text { Koefisien } \\
\text { Korelasi } \text { rhitung }\end{array}$ & Harga rtabel & Keputusan \\
\hline 1 & 0,639 & 0,301 & Valid \\
\hline 2 & 0,608 & 0,301 & Valid \\
\hline 3 & 0,691 & 0,301 & Valid \\
\hline 4 & 0,699 & 0,301 & Valid \\
\hline 5 & 0,619 & 0,301 & Valid \\
\hline 6 & 0,538 & 0,301 & Valid \\
\hline 7 & 0,377 & 0,301 & Valid \\
\hline 8 & 0,690 & 0,301 & Valid \\
\hline 9 & 0,611 & 0,301 & Valid \\
\hline 10 & 0,537 & 0,301 & Valid \\
\hline
\end{tabular}

Sumber : data diolah, 2015

a) Dilihat dari tabel hasil perhitungan uji validitas diatas bisa disimpulan bahwa variabel insentif $(X)$ Item 1 , dapat diketahui $r_{\text {hitung }}>$ dari $r_{\text {tabel }}$ dengan hasil 0,639 >0,301 maka dinyatakan valid.

b) Dari data diatas dapat dilihat hasil perhitungan uji validitas insentif item 2 , yaitu $r_{\text {hitung }}>$ dari $r_{\text {tabel }}$ dengan hasil $0,608>0,301$ maka dinyatakan valid.

c) Dari data diatas dapat dilihat hasil perhitungan uji validitas insentif item 3 , yaitu $r_{\text {hitung }}>$ dari $r_{\text {tabel }}$ dengan hasil $0,691>0,301$ maka dinyatakan valid.

d) Dari data diatas dapat dilihat hasil perhitungan uji validitas insentif item 4 , yaitu $r_{\text {hitung }}>$ dari $r_{\text {tabel }}$ dengan hasil $0,699>0,301$ maka dinyatakan valid.

e) Dari data diatas dapat dilihat hasil perhitungan uji validitas insentif item 5 , yaitu $r_{\text {hitung }}>$ dari $r_{\text {tabel }}$ dengan hasil $0,619>0,301$ maka dinyatakan valid.

f) Dari data diatas dapat dilihat hasil perhitungan uji validitas insentif item 6 , yaitu $r_{\text {hitung }}>$ dari $r_{\text {tabel }}$ dengan hasil 0,538>0,301 maka dinyatakan valid.

g) Dari data diatas dapat dilihat hasil perhitungan uji validitas insentif item 7 , yaitu $r_{\text {hitung }}>$ dari $r_{\text {tabel }}$ dengan hasil $0,377>0,301$ maka dinyatakan valid.

h) Dari data diatas dapat dilihat hasil perhitungan uji validitas insentif item 8 , yaitu $r_{\text {hitung }}>$ dari $r_{\text {tabel }}$ dengan hasil $0,690>0,301$ maka dinyatakan valid. i) Dari data diatas dapat dilihat hasil perhitungan uji validitas insentif item 9 , yaitu $r_{\text {hitung }}>$ dari $r_{\text {tabel }}$ dengan hasil $0,611>0,301$ maka dinyatakan valid.

j) Dari data diatas dapat dilihat hasil perhitungan uji validitas insentif item10, yaitu $r_{\text {hitung }}>$ dari $r_{\text {tabel }}$ dengan hasil 0,537>0,301 maka dinyatakan valid

Dari hasil uji coba instrumen penelitian yang dicobakan kepada 43 orang responden diperoleh kesimpulan bahwa 10 item pertanyaan valid. Dengan demikian kuesioner dapat digunakan sebagai alat untuk menganalisis data dari penelitian ini.

\section{2) Hasil Uji Validitas Variabel Produktivitas Kerja (Y)}

Uji validitas adalah untuk mengetahui sejauh mana suatu alat ukur mampu mengukur apa yang ingin diukur. Uji validitas diperoleh dengan cara mengkorelasikan setiap skor indikator dengan total skor indikator variabel, kemudian hasil korelasi dibandingkan dengan nilai kritis pada taraf signifikan 0.05. Suatu instrumen dikatakan valid apabila mampu mengukur apa yang diinginkan dan tinggi rendahnya validitas instrument menunjukan sejauh mana data yang terkumpul tidak menyimpang dari gambaran tentang variabel yang 
dimaksud. Cara yang digunakan adalah dengan analisis item, yaitu mengkorelasikan tiap skor, tiap butir dengan skor total yang merupakan jumlah tiap skor butir.

A. Menghitung Pearson's Product Moment

Berikut menghitung pearson's product moment dalam setiap butir item :

\section{Butir Item 1}

$$
\begin{aligned}
& r_{x y}=\frac{n \sum x y-\left(\sum x\right)\left(\sum y\right)}{\sqrt{\left[n \sum x^{2}-\left(\sum x\right)^{2}\right]\left[n \sum y^{2}-\left(\sum y\right)^{2}\right]}} \\
& r_{x y}=\frac{43.6488-(170)(1622)}{\sqrt{\left.\left[43.696-(170)^{2}\right] 43.62320-(1622)^{2}\right]}} \\
& r_{x y}=\frac{278984-(275740)}{\sqrt{[(29928-28900)(2679760-2630884)]}} \\
& r_{x y}=\frac{3244}{\sqrt{50244528}}=\frac{3244}{7088,337464} \\
& r_{x y}=0,45765315442=\mathbf{0 , 4 5 8}
\end{aligned}
$$

\section{Butir Item 2}

$$
\begin{aligned}
& r_{x y}=\frac{n \sum x y-\left(\sum x\right)\left(\sum y\right)}{\sqrt{\left[n \sum x^{2}-\left(\sum x\right)^{2}\right]\left[n \sum y^{2}-\left(\sum y\right)^{2}\right]}} \\
& r_{x y}=\frac{43.6331-(165)(1622)}{\sqrt{\left[43.657-(165)^{2}\left[43.62320-(1622)^{2}\right]\right.}} \\
& r_{x y}=\frac{272233-(267630)}{\sqrt{[(28251-27225)(2679760-2630884)]}} \\
& r_{x y}=\frac{4603}{\sqrt{50146776}} r_{x y}=\frac{4603}{7081,438837} \\
& r_{x y}=0,65000914446=\mathbf{0 , 6 5 0}
\end{aligned}
$$

\section{Butir Item 3}

$$
r_{x y}=\frac{n \sum x y-\left(\sum x\right)\left(\sum y\right)}{\sqrt{\left[n \sum x^{2}-\left(\sum x\right)^{2}\right]}\left[n \sum y^{2}-\left(\sum y\right)^{2}\right]}
$$

$$
\begin{aligned}
& r_{x y}=\frac{43.5963-(154)(1622)}{\sqrt{\left[43.588-(154)^{2}\right]\left[43.62320-(1622)^{2}\right]}} \\
& r_{x y}=\frac{256409-(249788)}{\sqrt{[(25284-23716)(2679760-2630884)]}} \\
& r_{x y}=\frac{6621}{\sqrt{76637568}}=\frac{6621}{8754,288549} \\
& r_{x y}=0,75631502925=\mathbf{0 , 7 5 6}
\end{aligned}
$$

\section{Butir Item 4}

$$
\begin{aligned}
& r_{x y}=\frac{n \sum x y-\left(\sum x\right)\left(\sum y\right)}{\sqrt{\left[n \sum x^{2}-\left(\sum x\right)^{2}\right]\left[n \sum y^{2}-\left(\sum y\right)^{2}\right]}} \\
& r_{x y}=\frac{43.6030-(156)(1622)}{\sqrt{\left[43.594-(156)^{2}\left[43.62320-(1622)^{2}\right]\right.}} \\
& r_{x y}=\frac{259290-(253032)}{\sqrt{[(25542-24336)(2679760-2630884)]}} \\
& r_{x y}=\frac{6258}{\sqrt{58944456}}=\frac{6258}{7677,52929} \\
& r_{x y}=0,81510597532=\mathbf{0 , 8 1 5}
\end{aligned}
$$

\section{Butir Item 5}

$$
\begin{aligned}
& r_{x y}=\frac{n \sum x y-\left(\sum x\right)\left(\sum y\right)}{\sqrt{\left[n \sum x^{2}-\left(\sum x\right)^{2}\right]\left[n \sum y^{2}-\left(\sum y\right)^{2}\right]}} \\
& r_{x y}=\frac{43.6051-(157)(1622)}{\sqrt{\left[43.599-(157)^{2}\left[43.62320-(1622)^{2}\right]\right.}} \\
& r_{x y}=\frac{260193-(254654)}{\sqrt{[(25757-24649)(2679760-2630884)]}} \\
& r_{x y}=\frac{5539}{\sqrt{54154608}}=\frac{5539}{7358,981451} \\
& r_{x y}=0,75268568576=\mathbf{0 , 7 5 3}
\end{aligned}
$$

\section{Butir Item 6}

$$
\begin{aligned}
r_{x y} & =\frac{n \sum x y-\left(\sum x\right)\left(\sum y\right)}{\sqrt{\left[n \sum x^{2}-\left(\sum x\right)^{2}\right]\left[n \sum y^{2}-\left(\sum y\right)^{2}\right]}} \\
r_{x y} & =\frac{43.5897-(153)(1622)}{\sqrt{\left[43.571-(153)^{2}\left[43.62320-(1622)^{2}\right]\right.}}
\end{aligned}
$$




$$
\begin{aligned}
& r_{x y}=\frac{253571-(248166)}{\sqrt{[(24553-23409)(2679760-2630884)]}} \\
& r_{x y}=\frac{5405}{\sqrt{55914144}}=\frac{5405}{7477,576078} \\
& r_{x y}=0,72282781794=\mathbf{0 , 7 2 3}
\end{aligned}
$$

\section{Butir Item 7}

$$
\begin{aligned}
& r_{x y}=\frac{n \sum x y-\left(\sum x\right)\left(\sum y\right)}{\sqrt{\left[n \sum x^{2}-\left(\sum x\right)^{2}\right]\left[n \sum y^{2}-\left(\sum y\right)^{2}\right]}} \\
& r_{x y}=\frac{43.6009-(156)(1622)}{\sqrt{\left[43600-(156)^{2}\left[43.62320-(1622)^{2}\right]\right.}} \\
& r_{x y}=\frac{258387-(253032)}{\sqrt{[(25800-24336)(2679760-2630884)]}} \\
& r_{x y}=\frac{5355}{\sqrt{71554464}}=\frac{5355}{8458,987173} \\
& r_{x y}=0,63305451237=\mathbf{0 , 6 3 3}
\end{aligned}
$$

\section{Butir Item 8}

$$
\begin{aligned}
& r_{x y}=\frac{n \sum x y-\left(\sum x\right)\left(\sum y\right)}{\sqrt{\left[n \sum x^{2}-\left(\sum x\right)^{2}\right]\left[n \sum y^{2}-\left(\sum y\right)^{2}\right]}} \\
& r_{x y}=\frac{43.6604-(173)(1622)}{\sqrt{\left[43.717-(173)^{2}\left[43.62320-(1622)^{2}\right]\right.}} \\
& r_{x y}=\frac{283972-(280606)}{\sqrt{[(30831-29929)(2679760-2630884)]}} \\
& r_{x y}=\frac{3366}{\sqrt{44086152}}=\frac{3366}{6639,741356} \\
& r_{x y}=0,50694745766=\mathbf{0 , 5 0 7}
\end{aligned}
$$

\section{Butir Item 9}

$$
\begin{aligned}
& r_{x y}=\frac{n \sum x y-\left(\sum x\right)\left(\sum y\right)}{\sqrt{\left[n \sum x^{2}-\left(\sum x\right)^{2}\right]\left[n \sum y^{2}-\left(\sum y\right)^{2}\right]}} \\
& r_{x y}=\frac{43.6445-(167)(1622)}{\sqrt{\left[43.681-(167)^{2}\left[43.62320-(1622)^{2}\right]\right.}} \\
& r_{x y}=\frac{277135-(270874)}{\sqrt{[(29283-27889)(2679760-2630884)]}} \\
& r_{x y}=\frac{6261}{\sqrt{68133144}}=\frac{5405}{8254,280344} \\
& r_{x y}=0,65481177943=\mathbf{0 , 6 5 5}
\end{aligned}
$$

10. Butir Item 10

$$
\begin{aligned}
& r_{x y}=\frac{n \sum x y-\left(\sum x\right)\left(\sum y\right)}{\sqrt{\left[n \sum x^{2}-\left(\sum x\right)^{2}\right]\left[n \sum y^{2}-\left(\sum y\right)^{2}\right]}} \\
& r_{x y}=\frac{43.6502-(171)(1622)}{\sqrt{\left.\left[43.703-(171)^{2}\right] 43.62320-(1622)^{2}\right]}} \\
& r_{x y}=\frac{279586-(277362)}{\sqrt{[(30229-29241)(2679760-2630884)]}}
\end{aligned}
$$$$
r_{x y}=\frac{2224}{\sqrt{48289488}}=\frac{2224}{6949,063822}
$$$$
r_{x y}=0,3200431104=\mathbf{0 , 3 2 0}
$$

B. Menentukan $r$ tabel Produktivitas $\operatorname{Kerja}(Y)$

Menentukan $r_{\text {tabel }}$ jika diketahui signifikan pada taraf nyata $\alpha=0,05$ dan $\mathrm{n}=43$, maka diperoleh $r_{\text {tabel }}=$ 0,301

\section{Menghitung Keputusan Uji Validitas}

Tabel berikut ini menyajikan keputusan uji validitas variabel produktivitas kerja: 
TABEL 2

KEPUTUSAN UJI VALIDITAS VARIABEL PRODUKTIVITAS KERJA

\begin{tabular}{|c|c|c|c|}
\hline $\begin{array}{c}\text { Nomor Item } \\
\text { Pertanyaan }\end{array}$ & $\begin{array}{c}\text { Koefisien } \\
\text { Korelasi } \text { rhitung }\end{array}$ & Harga $\mathbf{r}_{\text {tabel }}$ & Keputusan \\
\hline 1 & 0,458 & 0,301 & Valid \\
\hline 2 & 0,650 & 0,301 & Valid \\
\hline 3 & 0,756 & 0,301 & Valid \\
\hline 4 & 0,815 & 0,301 & Valid \\
\hline 5 & 0,753 & 0,301 & Valid \\
\hline 6 & 0,723 & 0,301 & Valid \\
\hline 7 & 0,633 & 0,301 & Valid \\
\hline 8 & 0,507 & 0,301 & Valid \\
\hline 9 & 0,655 & 0,301 & Valid \\
\hline 10 & 0,320 & 0,301 & Valid \\
\hline
\end{tabular}

Sumber: data diolah, 2015

a) Dilihat dari tabel hasil perhitungan uji validitas diatas bisa disimpulan bahwa variabel produktivitas kerja (Y) Item 1, dapat diketahui $r_{\text {hitung }}>$ dari $r_{\text {tabel }}$ dengan hasil $0,458>0,301$ maka dinyatakan valid.

b) Dari data diatas dapat dilihat hasil perhitungan uji validitas produktivitas kerja item 2, yaitu $r_{\text {hitung }}>$ dari $r_{\text {tabel }}$ dengan hasil $0,650>0,301$ maka dinyatakan valid.

c) Dari data diatas dapat dilihat hasil perhitungan uji validitas produktivitas kerja item 3, yaitu $r_{\text {hitung }}>$ dari $r_{\text {tabel }}$ dengan hasil $0,756>0,301$ maka dinyatakan valid.

d) Dari data diatas dapat dilihat hasil perhitungan uji validitas produktivitas kerja item 4, yaitu $r_{\text {hitung }}>$ dari $r_{\text {tabel }}$ dengan hasil $0,815>0,301$ maka dinyatakan valid.

e) Dari data diatas dapat dilihat hasil perhitungan uji validitas produktivitas kerja item 5, yaitu $r_{\text {hitung }}>$ dari $r_{\text {tabel }}$ dengan hasil $0,753>0,301$ maka dinyatakan valid.

f) Dari data diatas dapat dilihat hasil perhitungan uji validitas produktivitas kerja item 6, yaitu $r_{\text {hitung }}>$ dari $r_{\text {tabel }}$ dengan hasil $0,723>0,301$ maka dinyatakan valid.

g) Dari data diatas dapat dilihat hasil perhitungan uji validitas produktivitas kerja item 7 , yaitu $r_{\text {hitung }}>$ dari $r_{\text {tabel }}$ dengan hasil $0,633>0,301$ maka dinyatakan valid.

h) Dari data diatas dapat dilihat hasil perhitungan uji validitas produktivitas kerja item 8 , yaitu rhitung $>$ dari $r_{\text {tabel }}$ dengan hasil $0,507>0,301$ maka dinyatakan valid.

i) Dari data diatas dapat dilihat hasil perhitungan uji validitas produktivitas kerja item 9, yaitu rhitung $>$ dari $r_{\text {tabel }}$ dengan hasil $0,655>0,301$ maka dinyatakan valid.

j) Dari data diatas dapat dilihat hasil perhitungan uji validitas produktivitas kerja item 10,yaitu $r_{\text {hitung }}>$ dari $r_{\text {tabel }}$ dengan hasil $0,320>0,301$ maka dinyatakan valid

Dari hasil uji coba instrumen penelitian yang dicobakan kepada 43 orang responden diperoleh kesimpulan bahwa 10 item pertanyaan valid. Dengan demikian kuesioner dapat digunakan sebagai alat untuk menganalisis data dari penelitian ini.

\section{2) Hasil Uji Reliabilitas}

A. Hasil Uji Reliabilitas Variabel Insentif $(X)$

Instrumen reliabilitas adalah Instrumen yang digunakan beberapa kali untuk mengukur objek yang sama,akan menghasilkan data yang sama. Sugiyono (2011:348). 
Pengujian reliabilitas instrumen dapat dilakukan dengan teknik belah dua dari Spearman Brown (split half) dengan rumus sebagai berikut : Sugiyono ( $2011: 359)$.

$r i=\frac{2 . r_{b}}{1+r_{b}}$

Dimana:

$r_{i}=$ reliabilitas interval seluruh instrumen

$r_{b}=$ Korelasi product moment antara belahan pertama dan kedua

Nilai yang diperoleh tersebut kemudian dibandingkan dengan angka penerimaan reliabilitas sebesar 0,6. Priyatno (2010:98) menjelaskan reliabilitas kurang dari 0,6 adalah kurang baik, sedangkan 0,7 dapat diterima dan diatas 0,8 adalah baik.

Mengorelasikan Data Genap Dan Ganjil

$$
\begin{aligned}
& r_{x y}=\frac{n\left(\sum x y\right)-\left(\sum x\right)\left(\sum y\right)}{\sqrt{\left[n\left(\sum x^{2}\right)-\left(\sum x\right)^{2}\right]\left[n\left(\sum y^{2}\right)-\left(\sum y\right)^{2}\right]}} \\
& r_{x y}=\frac{43(15180)-(796)(809)}{\sqrt{\left.\left[43(14982)-(796)^{2}\right] 43(15455)-(809)^{2}\right]}} \\
& r_{x y}=\frac{(652740)-(643964)}{\sqrt{[(644226)-(633616)][(664565)-(654481)]}} \\
& r_{x y}=\frac{8776}{\sqrt{(10610)(10084)}}=\frac{8776}{\sqrt{106991240}} \\
& r_{x y}=\frac{8776}{10343,65699} \\
& r_{x y}=0,84844267443=\mathbf{0 , 8 5}
\end{aligned}
$$

Selanjutnya hasil perhitungan pada belahan pertama dimasukan pada belahan kedua menggunakan rumus Spearman Brown, dengan perhitunngan sebagai berikut :

$$
\begin{aligned}
& r_{i}=\frac{2 r_{b}}{1+r_{b}} \\
& r_{i}=\frac{2(0,85)}{1+0,85}=\frac{1,7}{1,85}=\mathbf{0 , 9 2}
\end{aligned}
$$

Berdasarkan perhitungan Spearman Brown diatas dapat dilihat bahwa uji reliabilitas lebih besar dari 0,6 sebagai batasan penelitian maka semua butir instrumen pada masing masing variabel insentif adalah reliabel, dengan demikian semua butir instrumen dapat digunakan sebagai instrumen penelitian.

\section{B. Hasil Uji Reliabilitas Variabel Produktivitas Kerja ( $Y$ ) \\ Instrumen reliabilitas adalah} Instrumen yang digunakan beberapa kali untuk mengukur objek yang sama,akan menghasilkan data yang sama. Sugiyono (2011:348).

Pengujian reliabilitas instrumen dapat dilakukan dengan teknik belah dua dari Spearman Brown (split half) dengan rumus sebagai berikut : Sugiyono (2011:359).

Dimana :

$$
r_{i}=\frac{2 . r_{b}}{1+r_{b}}
$$

$r_{i}=$ reliabilitas interval seluruh instrumen

$r_{b}=$ Korelasi product moment antara belahan pertama dan kedua

Nilai yang diperoleh tersebut kemudian dibandingkan dengan angka penerimaan reliabilitas sebesar 0,6. Priyatno (2010:98) menjelaskan reliabilitas kurang dari 0,6 adalah kurang baik, sedangkan 0,7 dapat diterima dan diatas 0,8 adalah baik.

Penyelesaian :

$$
\begin{aligned}
& r_{x y}=\frac{n\left(\sum x y\right)-\left(\sum x\right)\left(\sum y\right)}{\sqrt{\left[n\left(\sum x^{2}\right)-\left(\sum x\right)^{2}\right]\left[n\left(\sum y^{2}\right)-\left(\sum y\right)^{2}\right]}} \\
& r_{x y}=\frac{43(15560)-(804)(808)}{\sqrt{\left.\left[43(15396)-(804)^{2}\right] 43(15804)-(808)^{2}\right]}} \\
& r_{x y}=\frac{(669080)-(649632)}{\sqrt{[(662028)-(646416)][(679572)-(652864)]}}
\end{aligned}
$$




$$
\begin{aligned}
& r_{x y}=\frac{19448}{\sqrt{(15612)(26708)}} \\
& r_{x y}=\frac{19448}{\sqrt{416965296}} r_{x y}=\frac{19448}{20419,72811} \\
& r_{x y}=0,95241228948=0,95
\end{aligned}
$$

Selanjutnya hasil perhitungan pada belahan pertama dimasukan pada belahan kedua menggunakan rumus Spearman Brown, dengan perhitunngan sebagai berikut :

$$
r_{i}=\frac{2 r_{b}}{1+r_{b}}=\frac{2(0,95)}{1+0,95}=\frac{1,92}{1,95}=0,98
$$

Berdasarkan perhitungan Spearman Brown diatas dapat dilihat bahwa uji reliabilitas lebih besar dari 0,6 sebagai batasan penelitian maka semua butir instrumen pada masing masing variabel produktivitas kerja adalah reliabel, dengan demikian semua butir instrumen dapat digunakan sebagai instrumen penelitian.

\section{3). Teknik Analisis Data}

A. Analisis Regresi Linier Sederhana Berdasarkan kuesioner yang telah disebarkan kepada responden pada CV CST Virtual System Singapore Region Sumatera mengenai insentif dan produktivitas kerja, maka penulis memperoleh data kemudian penulis akan mencari pengaruh antara variabel $X$ dan variabel $Y$ dengan cara mengelola data dengan menggunakan rumus regresi linier sederhana.

Menurut Sugiyono (2011 : 261) adapun rumus yang digunakan penelitian adalah :

$$
Y^{\prime}=\mathbf{a}+\mathbf{b X}
$$

Sedangkan untuk mencari nilai a dan $b$ digunakan rumus sebagai berikut

$$
\begin{aligned}
\bar{Y} & =\frac{\sum Y}{n} \\
\ddot{X} & =\frac{\sum X}{n} \\
b & =\frac{n \sum x y-\left(\sum x\right)\left(\sum y\right)}{n \sum X^{2}-\left(\sum x\right)^{2}}
\end{aligned}
$$

Perhitungan persamaan regresi linier sederhana menghasilkan persamaan $Y^{\prime}=6,666+0,832$ dengan perhitungan sebagai berikut :

$$
\begin{aligned}
b & =\frac{n\left(\sum x y\right)-\left(\sum x\right)\left(\sum y\right)}{n\left(\sum x^{2}\right)-\left(\sum x\right)^{2}} \\
& =\frac{43(61282)-(1605)(1622)}{43(60797)-(1605)^{2}} \\
& =\frac{2635126-2603310}{2614271-2576025} \\
& =\frac{31816}{38246}=\mathbf{0 , 8 3 2} \\
& =\frac{\sum y}{n}-b \frac{\sum x}{n} \\
& =\frac{1622}{43}-0,832 \frac{1605}{43}=\mathbf{6 , 6 6 6}
\end{aligned}
$$

Berdasarkan hasil perhitungan regresi linier sederhana diatas dapat diketahui persamaan nilai $a=6,666$ dan nilai $b=0,832$ sehingga menghasilakan persamaan $Y^{\prime}=6,666+0,832$ yang kemudian akan dilihat pengaruhnya antara veriabel Insentif terhadap variabel Produktivitas Kerja.

\section{B. Koefisien Korelasi}

Koefisien Korelasi yaitu untuk melihat kuat tidaknya hubungan antara veriabel Insentif dan Produktivitas Kerja, dengan perhitungan sebagai berikut:

$$
a=\bar{y}-b \ddot{X}
$$




$$
\begin{aligned}
& r=\frac{n \sum x y-\left(\sum x\right)\left(\sum y\right)}{\sqrt{\left[n \sum x^{2}-\left(\sum x\right)^{2}\left[n \sum y^{2}-\left(\sum y\right)^{2}\right]\right.}} \\
& r=\frac{43.61282-(1605)(1622)}{\sqrt{\left[43.60797-(1605)^{2}\left[43.62320-(1622)^{2}\right]\right.}} \\
& r=\frac{2635126-(2603310)}{\sqrt{[(2614271-2576025)(2679760-2630884)]}} \\
& r=\frac{31816}{\sqrt{(38246)(48876)}}=\frac{31816}{\sqrt{1869311496}} \\
& r=\frac{31816}{43235,53511}=0,73587617035=\mathbf{0 , 7 3 6}
\end{aligned}
$$

Berdasarkan hasil perhitungan nilai koefisien korelasi $(r)$ diatas dapat diketahui nilai $r=0,736$ yang berarti pengaruh Insentif terhadap Produktivitas Kerja CV CST Virtual System Singapore Region Sumatera adalah Kuat.

\section{Koefisien Determinasi}

Penelitian ini menggunakan koefisien determinasi untuk mengetahui kontribusi insentif terhadap variabel produktivitas kerja,dengan perhitungan sebagai berikut :

$$
\begin{aligned}
R & =r^{2} \times 100 \% \\
& =0,736^{2} \times 100 \%=\mathbf{5 4 , 1 7} \%
\end{aligned}
$$

Hal ini dapat diartikan bahwa variabel insentif berpengaruh terhadap produktivitas kerja sebesar $54,17 \%$ sedangkan sisanya 45,83\% (100\% $54,17)$ dipengaruhi oleh variabel lain yang tidak diteliti dalam penelitian ini.

\section{Pengujian Hipotesis}

Uji hipotesis dilakukan dengan uji t. Langkah-langkah pengujian hipotesis sebagai berikut :

1. Merumuskan hipotesisi nol dan hipotesis alternatif :

Ho : berarti tidak terdapat pengaruh insentif terhadap produktivitas kerja pada CV CST Virtual System Singapore Region Sumatera

Ho : berarti terdapat pengaruh insentif terhadap produktivitas kerja pada CV CST Virtual System Singapore Region Sumatera.

2. Menentukan taraf nyata $(a)$

Taraf nyata atau nilai tabel ditentukan dengan derajat bebas (df) $\mathrm{df}=\mathrm{n}-2$

$\mathrm{df}=\mathrm{n}-2$

$\mathrm{df}=43-2$

$\mathrm{df}=41$

$\mathrm{df}=2,020$

3. Menentukan kriteria pengujian

Ho diterima dan Ha ditolak apabila $t_{\text {hitung }} \leq \mathrm{t}_{\text {tabel }}$ berarti tidak ada pengaruh insentif terhadap produktivitas kerja pada CV CST Virtual System Singapore Region Sumatera. Ha diterima dan Ho ditolak apabila $t_{\text {hitung }} \geq t_{\text {tabel }}$ berarti terdapat pengaruh insentif terhadap produktivitas kerja pada CV CST Virtual System Singapore Region Sumatera.

4. Menentukan uji statistik

$$
\begin{aligned}
\text { Sxy } & =\sqrt{\frac{\sum y^{2}-a \sum y-b \sum x y}{n-2}} \\
& =\sqrt{\frac{62320-6,666(1622)-0,832(61282)}{43-2}} \\
& =\sqrt{\frac{521,124}{41}}=\sqrt{12,7103414634} \\
S x y & =3,565 \\
S b & =\frac{S x y}{\sqrt{\sum x^{2}-\left\{\left(\sum x\right)^{2} / n\right.}} \\
& =\frac{3,121}{\sqrt{60797-\left[(1605)^{2} / 43\right]}}
\end{aligned}
$$




$$
\begin{aligned}
& =\frac{3,121}{\sqrt{60797-59907,56}} \\
& =\frac{3,121}{\sqrt{889,44}}=\frac{3,121}{29,8235} \\
\mathrm{Sb} & =\mathbf{0 , 1 0 5} \\
\boldsymbol{t} & =\frac{\boldsymbol{b}-\boldsymbol{B O}}{\boldsymbol{S b}}=\frac{0,832-0}{0,105} \\
& =7,9238095238=\mathbf{7 , 9 2 4}
\end{aligned}
$$

5. Menyimpulkan apakah Ho diterima atau di tolak

Dalam penelitian ini pengujian hipotesisi menolak Ho dan menerima Ha karena thitung $>t_{\text {tabel }}$ yaitu 7,924 > 2,020 berarti terdapat pengaruh insentif terhadap produktivitas kerja pada CV CST Virtual System Singapore Region Sumatera.

Kesimpulan dari pembahasan diatas yaitu Korelasi menjelaskan hubungan antara variabel bebas (insentif) terhadap variabel terikat (produktivitas kerja). Koefisien korelasi (r) sebesar 0,736 berarti kuat dan positif maksudnya jika insentif meningkat maka variabel produktivitas kerja juga meningkat dan sebaliknya jika variabel insentif menurun maka variabel produktivitas kerja menurun.

Koefisien determinasi menjelaskan seberapa besar kontribusi yang diberikan oleh variabel bebas (insentif) terhadap variabel terikat (produktivitas kerja). Nilai koefisien determinasi sebesar $54,17 \%$ berarti kontribusi variabel insentif terhadap produktivitas kerja sebesar 54,17\%, sedangkan sisanya 45,83\% (100\% $54,17 \%$ ) dijelaskan oleh variabel lain yang tidak diteliti dalam penelitian ini.

Analisis regresi dilakukan untuk mengetahui pengaruh variabel insentif (variabel bebas atau variabel $\mathrm{X}$ ) terhadap produktivitas kerja (variabel terikat atau variabel $Y$ ). Hasil perhitungan memperlihatkann persamaan regresi sederhana $Y^{\prime}=$ $6,666+0,832 X$.

Nilai koefisien korelasi regresi $\mathrm{a}=$ 6,666 berarti jika variabel $X$ atau insentif sebesar 0 satuan atau tidak terdapat variabel insentif, maka variabel $Y$ atau produktivitas kerja adalah sebesar nilai a yaitu 6,666 satuan. Nilai koefisien regresi $b=0,832$ berarti jika variabel $X$ atau insentif meningkat maka variabel $Y$ produktivitas kerja akan meningkat sebesar 0,832.

Menerima atau menolak hipotesis dilakukan dengan uji t pada taraf nyata $5 \%$ dengan dua variabel yaitu variabel bebas dan variabel terikat. Hasil penelitian terhadap uji hipotesis $t_{\text {hitung }}>$ ttabel yaitu 7,942>2,020 maka menghasilkan keputusan bahwa $\mathrm{Ho}$ ditolak dan $\mathrm{Ha}$ diterima, berarti terdapat pengaruh insentif terhadap produktivitas kerja pada CV CST Virtual System Singapore Region Sumatera.

\section{H. Kesimpulan dan Saran \\ 1. Kesimpulan}

Dari hasil analisis data yang telah dilakukan dapat ditarik kesimpulan sebagai berikut :

1) Koefisien korelasi sebesar 0,736 berarti kuat dan positif maksudnya jika insentif meningkat maka produktivitas kerja juga meningkat.

2) Koefisien determinasi sebesar $54,17 \%$ berarti kontribusi variabel insentif terhadap produktivitas kerja sebesar $54,17 \%$, sedangkan sisanya 45,83\% (100\% - 54,17\%) dijelaskan oleh variabel lain yang tidak diteliti dalam penelitian ini.

$\begin{array}{lll}\text { Persamaan regresi } & \text { linier } \\ \text { sederhana adalah } & Y^{\prime} & = \\ 6,666+0,832 X & \text { dengan nilai }\end{array}$


sebesar 6,666 berarti jika insentif sebesar 0 satuan maka produktivitas kerja sebesar 6,666 satuan, serta b sebesar 0,832 berarti jika insentif meningkat sebesar 1 satuan, maka produktivitas kerja meningkat 0,832 . Koefisien bernilai positif artinya terjadi hubungan positif antara insentif dengan produktivitas kerja, semakin tinggi insentif maka semakin meningkat produktivitas kerja.

4) Hasil pengujian hipotesis dengan menggunakan uji $\mathrm{t}$ dan nilai thitung $>$ tabel yaitu 7,924 > 2,020 maka Ho ditolak dan $\mathrm{Ha}$ diterima diperoleh kesimpulan bahwa terdapat pengaruh insentif terhadap produktivitas kerja pada CV CST Virtual System Singapore Region Sumatera.

\section{Saran}

1) Sebaiknya perusahaan dapat mempertahankan insentif untuk karyawan berprestasi karena dengan itu suatu hal yang positif untuk memotivasi karyawan agar bekerja dengan efektifitas dan efisien agar terwujudnya produktivitas kerja karyawan yang uggul.

2) Dalam pemberian insentif sebaiknya CV CST Virtual System Singapore Region Sumatera dapat mempertimbangkan bagi karyawan yang berprestasi agar dapat memacu para karyawan agar dapat meningkatkan produktivitas kerja, dan dapat bersaing dengan perusahaan lain yang mulai maju dari tahun sebelumnya.

\section{DAFTAR PUSTAKA}

Arikunto, Suharsimi. 2010. Prosedur Penelitian. Jakarta : Rineka Cipta.

Rivai, Veitzal. 2009. Manajemen Smber Daya Manusia Untuk Perusaahaan. Yogyakarta : Raja Grafindo Persada.

Sugiyono. 2010 . Metode Penelitian Kuantitatif,Kualitatif dan $R \& D$. Bandung : Alfabeta.

Sugiyono. 2011. Metode Penelitian Bisnis . Bandung : Alfabeta.

Sulistiyani, Teguh. 2010. Memahami Good Governance Dalam Perspektif Sumber Daya Manusia. Yogyakarta : Gaya Media.

Suwatno, priansa juni .2011. Manajemen SDM Dalam Organisasi Publik Dan Bisnis. Bandung : Alfabeta.

Yani, Muhammad. 2012. Manajemen Sumber Daya Manusia. Jakarta : Mitra Waca Media. 